\title{
III. Lupus Erythematosus (1) Immunopathological Study on Lupus Nephritis
}

\author{
Noriyuki Kurata, MD and Tadashi OfujI, MD \\ The Third Department of Internal Medicine Okayama University \\ Medical School, Okayama 700
}

It has been reported that antibody to double stranded(ds)-DNA may form circulating immune complex and cause the nephritis in patients with systemic lupus erythematosus $(\mathrm{SLE})^{1,2)}$. On the other hand, findings obtained from New Zealand mice has suggested the possibility that immune complex involving $\mathrm{G}$ type viral antigens may cause the nephritis even in human $\mathrm{SLE}^{3)}$.

In this paper, the correlation of immunopathological findings on lupus nephritis with serological abnormalities and clinical manifestations of renal disease in SLE was studied. Some of the pathogenetical aspects on lupus nephritis were also dicussed.

\section{MATERIALS AND METHODS}

A total of 219 renal tissues obtained from 141 patients with SLE were examined by immunofluorescent technique. Antisera for immunofluorescent technique were FITC labelled antibodies to human $\operatorname{IgG}, \operatorname{Ig} M$, $\operatorname{Ig} \mathrm{A}, \operatorname{IgE}, \mathrm{Clq}, \mathrm{C} 4, \mathrm{C} 3$ and fibrinogen.

Immunological abnormalities were tested in sera obtained at acute stage prior to renal biopsy. Antibody to ds-DNA was measured by $50 \%$ ammonium sulphate method using $\left({ }^{3} \mathrm{H}\right)$ Actinomycin D-DNA. Antibodies to nuclear acidic nucleoprotein (Sm) and nuclear ribonucleoprotein (RNP) were determined by sensitive method reported previously ${ }^{4)}$. Seven kidneys obtained at autopsy were subjected to the elution study according to the method descrbed before ${ }^{2)}$.

\section{RESULTS}

1) Immunofluorescent glomerular stainings. Althogh immunopathological findings of lupus nephritis were heterogeneous, 5 distinct staining patterns were classified on the basis of the presence of granular immune deposits on glomeruli.

Briefly, linear pattern showed contenuous staing of $\operatorname{IgG}$ along the glomerular basement membrane (GBM). In mesangial pattern, immune deposits were localized in mesangium. Membranuous pattern showed the presence of subepithelial immune deposits. Granular pattern showed immune deposits localized in subendothelial site of GBM and mesangium. Subepithelial immune deposits were also found in various degree. Massive deposition of subendothelial and mesangial immune deposits caused marked narrowing and obstruction of capillary tufts in lumpy pattern.

The incidence of each classified groups. of 141 initial renal biopsies was following; granular pattern was $18 \%$, mesangial pattern was $18 \%$, membranous pattern was $11 \%$, granular pattern was $40 \%$, lumpy pattern was $13 \%$.

2) Immunofluorescent classifications and immunoserological abnormalities.

As demonstrated in Table 1, significant elevation of the mean value of ds-DNA binding was found in groups of granular and lumpy pattern while slight elevation of the binding was observed in other 3 groups. 
Table 1. Correlation of Immunofluorescent Glomerular Stainings with Immunological Abnormalities.

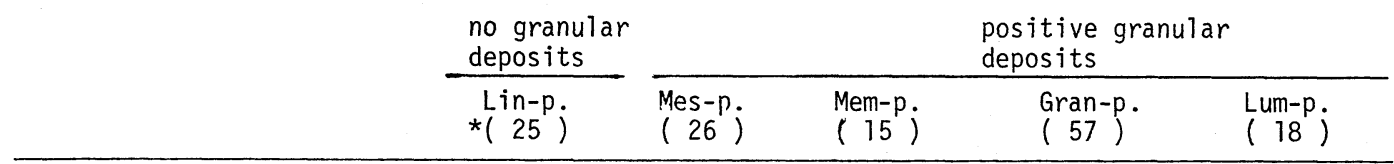

\begin{tabular}{|c|c|c|c|c|c|c|}
\hline \multirow{2}{*}{$\begin{array}{l}\text { ds-DNA binding(\%) } \\
(M \pm S D)\end{array}$} & & $20.52 \pm 11.08$ & \multirow{2}{*}{$\begin{aligned} & 22.48 \pm 10.30 \\
& P<0.05 \\
& P<0.01\end{aligned}$} & \multirow{2}{*}{$\underline{16.38 \pm 9.18}$} & \multirow[t]{2}{*}{$30.98 \pm 20.40$} & \multirow[t]{2}{*}{$40.32 \pm 79.49$} \\
\hline & & & & & & \\
\hline \multirow{3}{*}{$\begin{array}{c}\text { positive incidence } \\
\text { of } \\
\text { antibodies } \\
\text { to }\end{array}$} & \multirow{2}{*}{$\mathrm{Sm}$} & $8.0 \%$ & $42.0 \%$ & $42.9 \%$ & $35.1 \%$ & $38.9 \%$ \\
\hline & & & \multicolumn{4}{|c|}{$P<0.01 \longrightarrow(38.8 \%)$} \\
\hline & RNP & $40.0 \%$ & $73.0 \%$ & $64.3 \%$ & $52.1 \%$ & $55.6 \%$ \\
\hline $\mathrm{CH} 50(M \pm S D)$ & \multicolumn{2}{|r|}{$\frac{27.45 \pm 6.70}{L P<0.01}$} & $\frac{15.26 \pm 70.34}{1}$ & $23.82 \pm 8.92$ & $\frac{14.95 \pm 9.62}{1}$ & $\frac{9.94 \pm 6.53}{1}$ \\
\hline
\end{tabular}

*( ) : patients number

Lin-p.; linear pattern, Mes-p.; mesangial pattern, Mem-p.; membranous pattern Gran-p.; granular pattern, Lum-p.; lumpy pattern.

The incidence of precipitating antibody to $\mathrm{Sm}$ was $8 \%$ in group of linear pattern and $38.8 \%$ in other 4 groups. This difference was statistically different. The incidence of precipitating antibody to RNP in 5 groups was from 40 to $73 \%$. Groups of mesangial and membranous pattern tended to have high frequencies of this antibody.

Marked decrease of $\mathrm{CH} 50$ was found in groups of mesangial, granular and lumpy pattern. The mean values of $\mathrm{CH} 50$ in these 3 groups were significantly low compared with that in linear pattern.

3) Renal disease and immunoserological abnormalities.

Thirty three patients showed 37 times of exacerbations of renal disease during their clical courses. Significant increase of ds-DNA binding was found in 15 Of 37 exacerbations (41\%). Marked decrease of CH50 was, on the other hand, in 35 of 37 $(91 \%)$.

In this series, 15 patients were diagnosed lupus nephritis non-related to ds-DNA antibody. Multiple tests on those sera obtained at various stages including prior to therapy showed no abnormal ds-DNA binding. Antibodies to Sm, RNP and other nuclear antigens were detected in these sera with different frequencies. Serum complement levels in 11 of 15 were less than 20. Renal biopsies revealed that diffuse proliferative lupus nephritis was in 8 , membranous lupus nephritis was in 5 . Immunopathologically glomerular immune deposits were demonstrated in all of 15 patients.

4) Elution study.

Antibody to ds-DNA was eluted in 3 Of 7 acid treated specimens from diseased kidneys. More frequently, antibodies to $\mathrm{Sm}$ and RNP were detected in the same eluates.

\section{DISCUSSION}

The present study suggests some interesting feature about the role of antibodies to specific nuclear antigens in lupus nephritis. Prior to this study, it was our impression that there might be several systems participating in pathogenesis of lupus nephritis because the greate varieties of histological findings and renal manifesta- 
tions had been widely observed.

Close correlation of elevated ds-DNA binding with the renal disease in SLE was confirmed in our study. Fifteen patients who had definite renal diseases showed negative tests for antibody to ds-DNA irrespective of the positive glomerular immune deposits. Antibodies to various nuclear antigens other than ds-DNA were detected in these sera. Additional observation to be discussed is that $41 \%$ of exacerbation of lupus nephritis associated with increase of ds-DNA binding while 95\% were associated with marked decrease of CH50. It is difficult to explain the mechanism of renal involvement by any theory of ds-DNA immune complex alone.

The incidence of antibody to $\mathrm{Sm}$ in group of linear pattern was definitely low. This antibody was detected in 47 of 141 patients. Forty five of $47(96 \%)$ were demonstrated to have glomerular immune deposits.

It has been reported that antibody to RNP is rarely found in patients with SLE who have severe lupus nephritis and this same antibody occurs frequently in those with no renal diseases ${ }^{5}$. The incidence of this antibody has prviously stated to approximately $30 \%$ in SLE. Contrary to this, we found the incidence of antibody to RNP was $55.3 \%$ in SLE. Positive rate of this antibody was more than $50 \%$ even in patients who have severe renal diseases proved by histological and immunopathological study.

Since no one has succeeded to demonstrate $\mathrm{Sm}$ and RNP antigens on diseased glomeruli, direct evidence of immune complexes involving antibodies to $\mathrm{Sm}$ and RNP is still under investigation. One of the most important findings in this study is that antibodies to $\mathrm{Sm}$ and RNP are eluted from diseased kidneys more frequently than antibody to ds-DNA.

Our observations indicate that autoantibodies to various nuclear antigens present in lupus sera may cause the heterogeneity of histological and immunopathological findings of lupus nephritis. Antibodies to $\mathrm{Sm}$ and RNP are also of importance in pathogenesis of lupus nephritis in addition to already accepted role of antibody to ds-DNA.

\section{REFERENCES}

1) Tan EM, Schur PH, et al: Deoxyribonucleic acid (DNA) and antibody to DNA in the serum of patients with systemic lupus erythematosus. J Clin Invest 45 : 1732, 1966.

2) Koffler D, Schur PH, et al: Immunological studies concerning the nephritis of systemic lupus erythematosus. J Exp Med 126: 607, 1969.

3) Yoshiki R, Mellors RG, et al: The viral envelope glycoprotein of murine leukemia virus and pahtogenesis of immune complex nephritis of New Zealand mice. J Exp Med $140: 1011,1974$.

4) Kurata $\mathrm{N}$ and Tan EM: Identification of antibodies to nuclear acidic antigeng by counter-immunoectrophoresis. Arthritis Rheum 19: 504, 1976.

5) Reichlin $\mathrm{M}$ and Mattioli $\mathrm{M}$ : Correlation of precipitin reaction to RNA protein antigen and a low prevalence of nephritis in patients with systemic lupus erythematosus. New Engl J Med 27 : 908, 1972. 